\title{
Modelling of Hydraulic Spool-Valves with Specially Designed Metering Edges
}

\author{
Marko Šimic* - Mihael Debevec - Niko Herakovič \\ University of Ljubljana, Faculty of Mechanical Engineering, Slovenia
}

\begin{abstract}
This paper presents a new approach for modelling and simulation of hydraulic spool valves by using the already known simple mathematical expressions for describing the sliding spool geometry. The main objective of the research is to divide the hydraulic sliding spool into functional elements which can be described analytically. Such models can be implemented as micro components into any hydraulic simulation tool's library. By using such an approach, hydraulic valves can be designed very flexibly, with different shapes of spool metering edges in combination with other functional elements. The user can quickly find the most appropriate spool construction for the desired hydraulic system performance. This can be done in advance, before designing the real system. The paper deals with and presents only one of the several different geometrical shapes of spool metering edges and the corresponding mathematical models of the volume flow characteristics that we have developed. Simulation results are verified and confirmed with experimental tests using a real valve geometry.
\end{abstract}

Keywords: hydraulic spool valve, spool notch geometry, mathematical modelling, simulation model

\section{INTRODUCTION}

The development of new advanced hydraulic systems and their components consists mainly of two approaches. The first approach, which is based on an adequate tracking and intelligent closed loop control using adaptive feedback systems, satisfies most of the practical technical requirements for the quality of the dynamic behaviour of the hydraulic system [1] and [2]. The other approaches, such as direct numerical simulation using an immersed-boundary method [3] or three dimensional CFD analysis [4] and [5], provide more flexibility and reveal an opportunity for the development of new mechanical design solutions.

Many different types of spool valves assist in controlling the hydraulic fluid flow in hydraulic systems. The main function of the spool valve is to provide a desired balance in the system between the flow control and the pressure control. The improved dynamic behaviour of the system and its desired functionality are possible because of the use of hydraulic valves with specially designed metering edges of the spool which allow precise pressure and flow control [6] and [7]. The new design is usually based on the use of dedicated computer simulation tools operated by experts. A single valve is normally described with a very small number of parameters which often do not meet all the simulation criteria. The missing parameters must be defined by using analytical or CFD simulation packages. Otherwise, experimental tests are necessary [8].

The main idea of our research is to divide the sliding spool of the valve into different modules which can be optionally put together by the user. This approach allows the user to design a valve with different metering edges of the spool and to quickly check through simulation how the valve influences the characteristics of a practical hydraulic system. When the results of the system characteristics satisfy the user's expectations, the real valve can be ordered at the valve producer by giving them the exact demands regarding the geometry of the valve, especially the sliding spool. Thus, the user can get the best possible design of the valve from the producer and achieve the best possible performance of the hydraulic system.

One of the very well-known commercial simulation tools appropriate especially to perform the simulation and the analysis of the static and dynamic behaviour of hydraulic and pneumatic systems and components is the DSHplus software [9].

The functional elements of the sliding spool valve dealt with in our research are intended to be implemented into MCL (Micro Component Library) of the DSHplus [9].

\section{MODELLING OF HYDRAULIC SPOOL VALVES}

The existing simulation valve models consist of classic sharp metering edges with mathematical models of linear volume flow rate characteristics without the possibility of modifications. The metering edge geometry is the key parameter for the determination of the volume flow characteristics. Sophisticated hydraulic valves require a new, advanced notch geometry of the spool, the characteristics of which are nonlinear [7].

The basic formula for the volume flow calculation is the orifice Eq. (1) [9]: 


$$
Q=\alpha_{D} \cdot A \cdot \sqrt{\frac{2 \cdot \Delta p}{\rho}},
$$

where the parameters are defined as follows; $Q$ is the volume flow $[1 / \mathrm{min}], \alpha_{D}$ the contraction flow coefficient [-], $A$ the cross-sectional area $\left[\mathrm{m}^{2}\right], \rho$ the density of the fluid $\left[\mathrm{kg} / \mathrm{m}^{3}\right]$, and $\Delta p$ the pressure difference across the metering edge [bar].

One of the main variables of Eq. (1) is the crosssectional area $A$ which is a function of the spool displacement and of the metering edge geometry.

An example of a real hydraulic valve with a specially designed sliding spool, used for pressure and flow control, is shown in Fig. 1 [7].

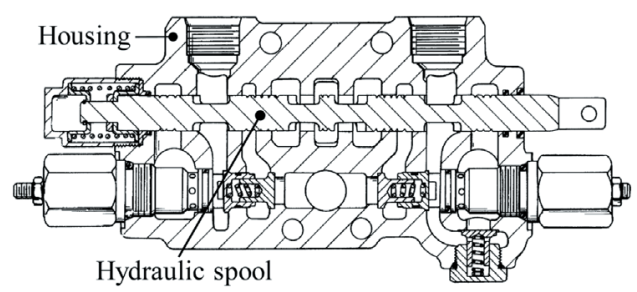

Fig. 1. Hydraulic valve with specially designed metering edges

The detailed view of the hydraulic sliding spool from Fig. 1 is presented in Fig. 2 [7]. The spool has six control edges with three different geometries which can be divided into three different functional elements or modules. Detail A shows the possible geometry of the metering edge. By describing geometrical dependencies separately for each metering edge of the spool analytically with simple mathematical expressions, it is possible to accurately describe the characteristics of the hydraulic valve as a whole through simulation. Thus, we do not need to perform an experimental test for each new valve geometry.
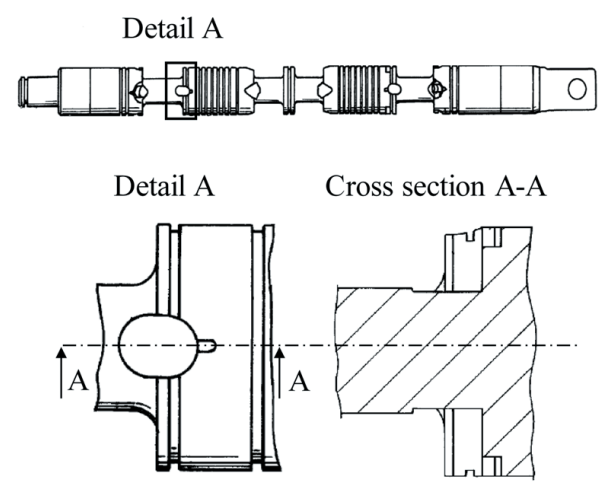

Fig. 2. Detail view of one specially designed metering edge of the hydraulic spool

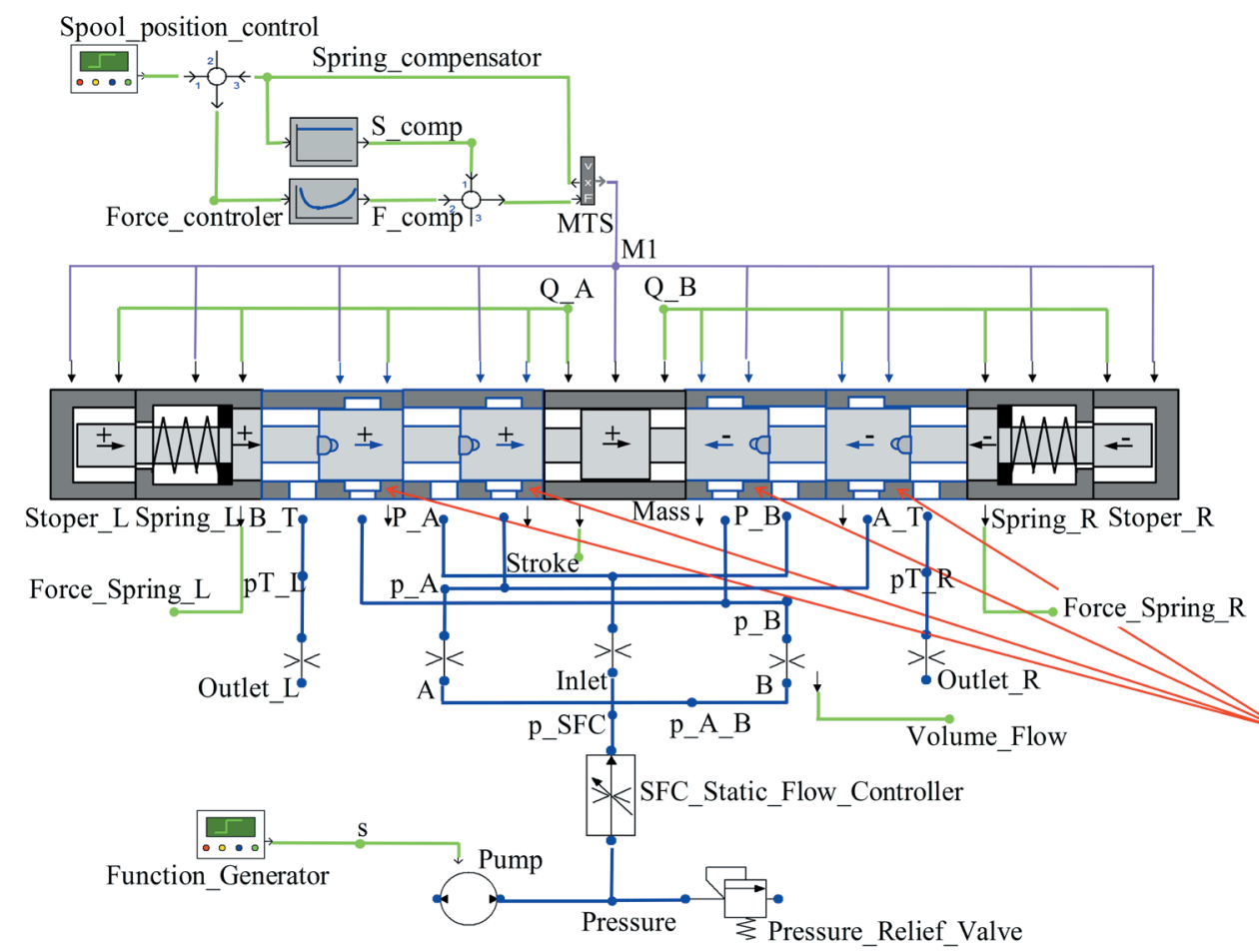

Fig. 3. The valve spool of Fig. 2 as sub-model in DSHplus valve model [8]
Micro Component Library functional elements

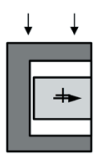

MC_Stoper

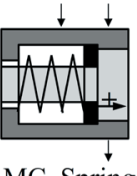

MC_Spring

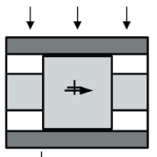

MC_Mass

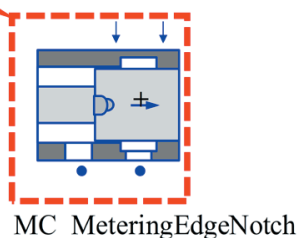


Fig. 3 presents the incorporated spool into the simulation valve model of the DSHplus tool by using various functional elements from its MCL.

Specific functional elements of the spool are: its mass, mechanical stops, springs, and the most important »Metering-Edge-Notched « elements with different geometries. Static and dynamic characteristics of the valve are mostly influenced by combining different functional elements together into the sliding spool.

The »Metering-Edge-Notched « element, marked with a rectangle in Fig. 3 (marked with thick doted red line), presents the element described in the background by the mathematical calculation of the volume flow across the notched metering edge area.

\section{ANALYTICAL MODELLING AND SIMULATION}

As the first step for the analytical modelling of the cross-sectional area $A$, the shape and the geometry of the metering edge of the real spool have to be defined. For this purpose, a 3D model of a hydraulic spool notch was designed in order to reach a better understanding of the direction and all the influential areas of the fluid flow during the spool displacement (Fig. 4).

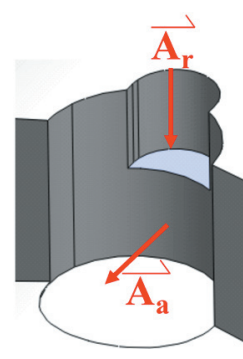

a)

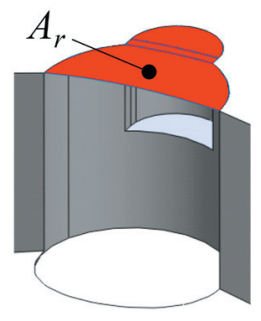

b)

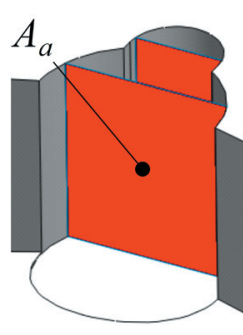

c)
Fig. 4. a) flow direction of the metering edge, b) radial and c) axial cross-sectional areas

In general, the 3D model shows that there are two types of fluid flow: radial flow going through the radial areas on the curvature of the spool and axial flow going through the axial areas on the face side of the spool. The direction of the flow is indicated by the flow vectors $\mathbf{A}_{\mathbf{r}}$ and $\mathbf{A}_{\mathbf{a}}$ in Fig. 4a. Figs. $4 \mathrm{~b}$ and c show the annotations for those two areas: the radial area segment is labelled as $A_{r}$ and the axial area segment as $A_{a}$. The fluid normally flows through the radial area first and then passes through the axial area into the hydraulic chamber.

For the mathematical calculation of the radial and axial cross-sectional areas of the spool metering edge, the curvature of the surface has to be taken into consideration to verify the possibility of geometry simplification.

A schematic presentation of the curved radial cross-sectional area is shown in Fig. 5a, while a simplified surface of the radial area is presented as a flat surface in Fig. 5 b.

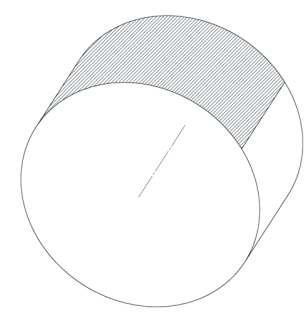

a)

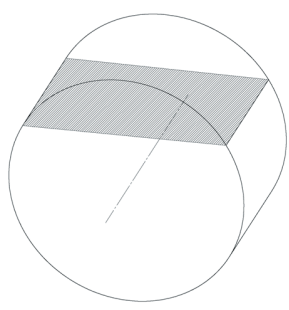

b)
Fig. 5. Schematic presentation of the radial cross-sectional area; a) curved and b) simplified

The schematic curved and simplified axial crosssectional areas shown in Figs. $6 \mathrm{a}$ and $\mathrm{b}$ present more or less a rectangle with a negligible curved area at the curvature line of the spool.

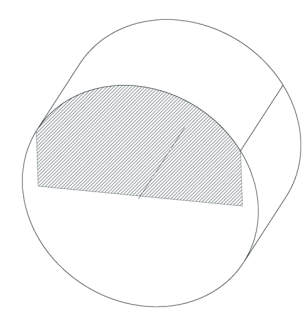

a)

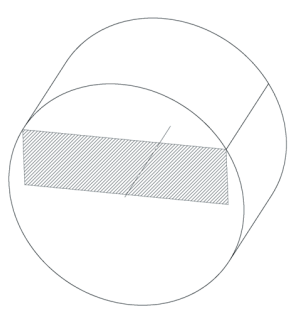

b)
Fig. 6. Schematic presentation of the axial cross-sectional area; a) curved and b) simplified

Assuming that the spool diameter is $16 \mathrm{~mm}$ (the nominal size 10 of a proportional valve) and the radii of the notch is less than $2 \mathrm{~mm}$, the curved areas presented in Fig. 5a and Fig. 6a can be neglected because the deviation between the real curved surface (Figs. 5a and 6a) and the simplified surface (Figs. 5b and $6 \mathrm{~b}$ ) is less than $0.5 \%$. The modelling is therefore simplified from 3D (three dimensional) surface models to 2D (two dimensional).

The real geometry of the flow control metering edge (notch) of the spool is marked as detail B in Fig. 7.

The metering edge consists of two different geometrical parts presented in Fig. 8: half circular pockets presented as areas $A_{1}$ and $A_{3}$ and a rectangular pocket presented as area $A_{2}$.

The mathematical description of the metering edge is therefore separated into the modelling of the circular and the rectangular areas. 


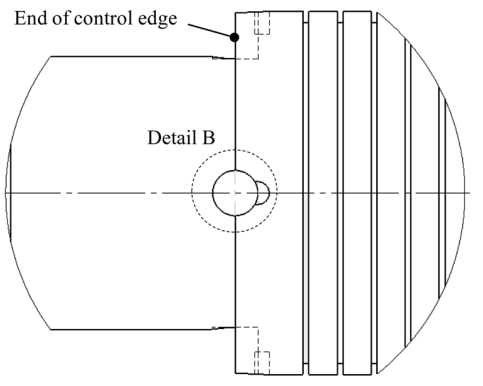

Fig. 7. The real metering edge of the sliding spool marked as detail $B$

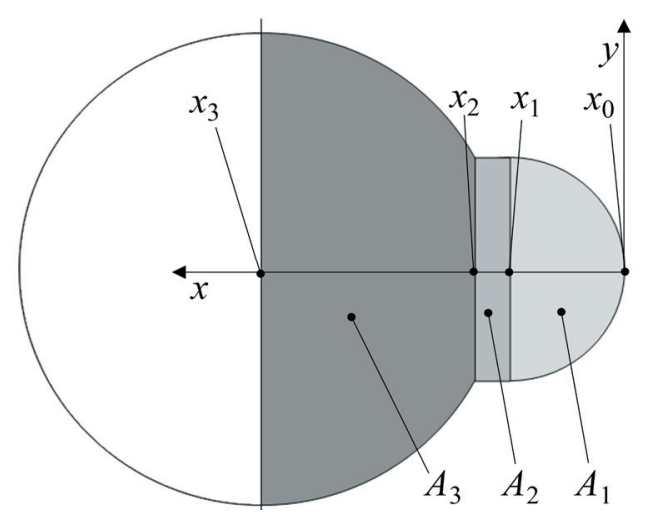

Fig. 8. The real metering edge of the sliding spool marked as detail $B$

Area $A_{1}$ as presented in Fig. 8 can be calculated by using simple, well-known trigonometric equations of the circular segment [10]. The detailed view and all the influential parameters are shown in Fig. 9.

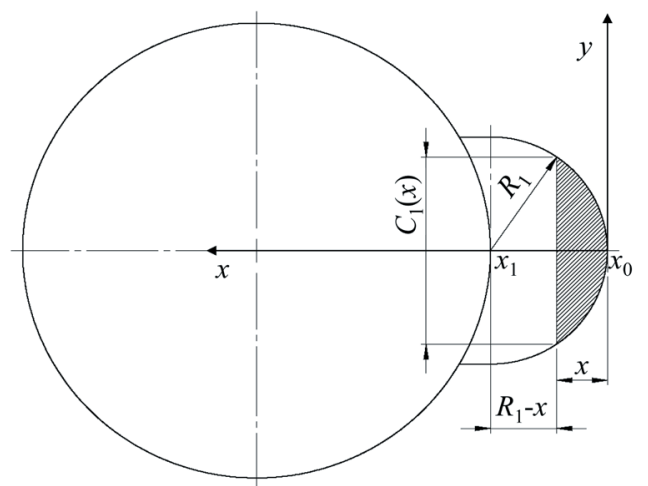

Fig. 9. Influential parameters of the circular area $A_{1}$

Radial circular area $A_{1 r}(x)$ depends on radii $R_{1}$ and on spool displacement $x_{0}<x<x_{1}$. It can be calculated by using Eq. (2) which is given simply by the area of the triangular portion subtracted from the circular sector of the entire wedge-shaped portion. Parameter $B$ in Eq. (2) stands for $R_{1}-x$.

$$
A_{1 r}(x)=R_{1}^{2} \arccos \left(\frac{B}{R_{1}}\right)-B \sqrt{2 \cdot R_{1} \cdot x-x^{2}} .
$$

Axial circular segment area $A_{1 a}(x)$ for the same range of spool displacement $x_{0}<x<x_{1}$ can be calculated with Eq. (3):

$$
A_{1 a}(x)=C_{1}(x) \cdot h_{1},
$$

where $h_{1}$ represents the depth of the circular pocket $A_{1}$, and $C_{1}(x)$ is given by Eq. (4):

$$
C_{1}(x)=2 \cdot \sqrt{2 \cdot R_{1} \cdot x-x^{2}} .
$$

The area $A_{2}$ from Fig. 8 is shown in detail in Fig. 10. It represents the rectangular area for spool displacements from $x_{1}$ to $x_{2}$ where the mathematical formulation of the radial geometry is simple and therefore the mathematical model does not require a detailed analysis.

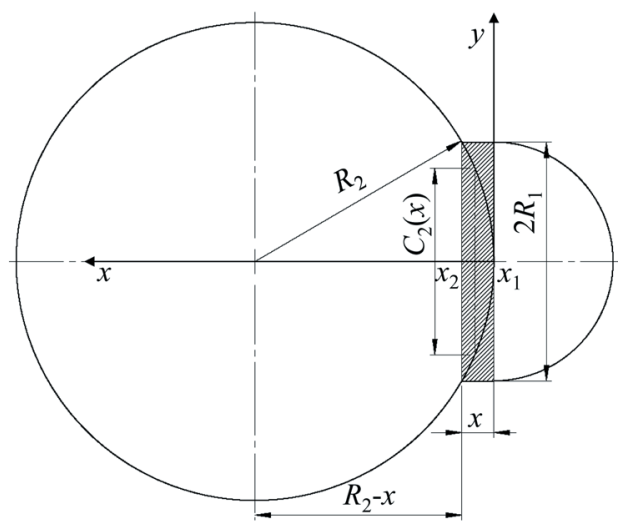

Fig. 10. Influential parameters of rectangular area $A_{2}$

By taking into account the geometrical parameters $\left(R_{1}, R_{2}, h_{1}\right.$ and $\left.h_{2}\right)$ presented in Fig. 10 and the spool displacement range $x_{1}<x<x_{2}$, the mathematical model for radial cross-sectional area $A_{2 r}(x)$ can be described with Eq. (5).

$$
A_{2 r}(x)=2 \cdot R_{1} \cdot x .
$$

Spool displacement $x_{2}$ is given by Eq. (6).

$$
x_{2}=R_{2}-\sqrt{R_{2}^{2}-\left(R_{2}-x\right)^{2}} .
$$

Total axial area $A_{2 a}(x)$ (Fig. 11) can be divided into two areas. The first one represents the constant rectangular area which depends on $R_{1}$ and on depth of the pocket $h_{1}$ while the second area depends on $C_{2}(x)$ and on depth $h_{2}-h_{1}$. 


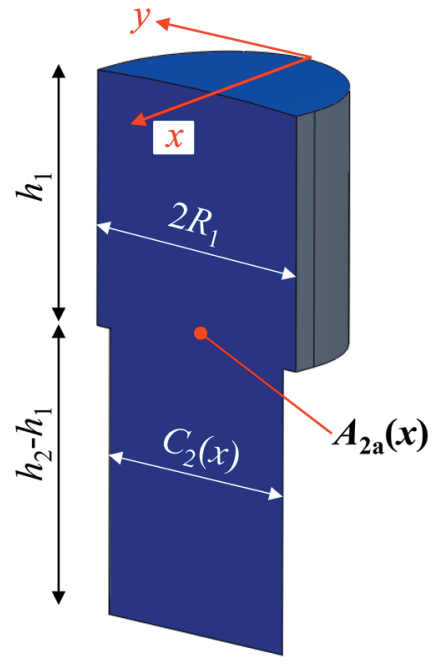

Fig. 11. Geometry of axial area $A_{2 a}(x)$

Total axial area $A_{2 a}(x)$ is represented with Eq. (7) where $C_{2}(x)$ can be calculated with Eq. (8).

$$
\begin{gathered}
A_{2 a}(x)=2 \cdot R_{1} \cdot h_{1}+C_{2}(x) \cdot\left(h_{2}-h_{1}\right), \\
C_{2}(x)=2 \cdot \sqrt{2 \cdot R_{2} \cdot x-x^{2}} .
\end{gathered}
$$

The area $A_{3}$ from Fig. 8 is defined in a similar way as area $A_{1}$. The radial and axial cross-sectional areas consist of the parameters presented in Fig. 12.

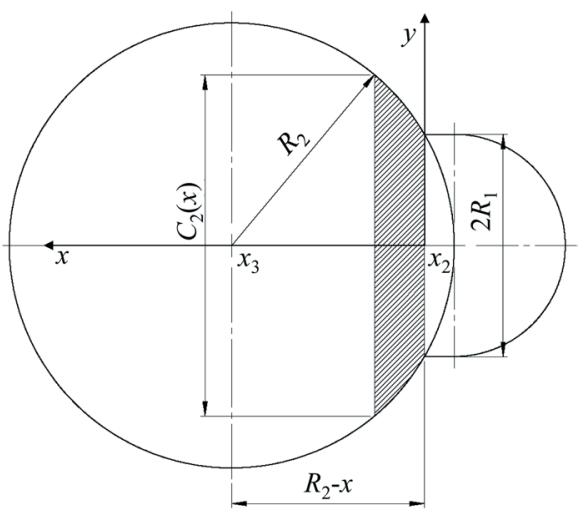

Fig. 12. Geometry of the circular area $A_{3}$

A final equation for the radial cross-sectional area $A_{3 r}(x)$ for spool displacement $x_{2}<x<x_{3}$ can be written as:

$$
A_{3 r}(x)=R_{2}^{2} \arccos \left(\frac{D}{R_{2}}\right)-D \sqrt{2 \cdot R_{2} \cdot x-x^{2}},
$$

where $D$ stands for $R_{2}-x$.
Axial circular segment area $A_{3 a}(x)$ for spool displacement $x_{2}<x<x_{3}$ is given by Eq. (10):

$$
A_{3 a}(x)=C_{2}(x) \cdot h_{2} \text {, }
$$

where $h_{2}$ represents the depth of the $A_{3}$ pocket, and $C_{2}(x)$ is already given with Eq. (8).

The final mathematical model of the total radial and axial cross-sectional areas (Eqs. (11) and (12)) is taking into account the spool displacement from the beginning of the spool metering edge $x_{0}$ to the end of the metering edge $x_{3}$ as shown in detail B of Fig. 8 .

Total radial area $A_{r}$ is determined as the sum of all radial areas and increases incrementally as described with the formulae of the individual segments.

$$
A_{r}=n \cdot\left(A_{1 r}+A_{2 r}+A_{3 r}\right) .
$$

Total axial area $A_{a}$ is determined as the minimal axial cross-sectional area at a given spool position $x_{i}$ $\left(i=x_{0}, \ldots, x_{3}\right.$, Fig. 6). Parameter $n$, considered in Eqs. (11) and (12), represents the total number of notches.

$$
A_{a}=n \cdot\left[\min \left(A_{1 a}, A_{2 a}, A_{3 a}\right)\right] .
$$

The volume flow characteristics $Q\left(A_{r}\right)$ and $Q\left(A_{a}\right)$ presented in Fig. 14 are calculated by using the final mathematical models of radial and axial crosssectional areas $A_{r}$ and $A_{a}$ in Eq. (1). The volume flow rate is calculated for 24 discrete points of the spool displacement from $x=0$ to $x=1.5 \mathrm{~mm}$. All other influential parameters considered in Eq. (1) are shown in Fig. 13.

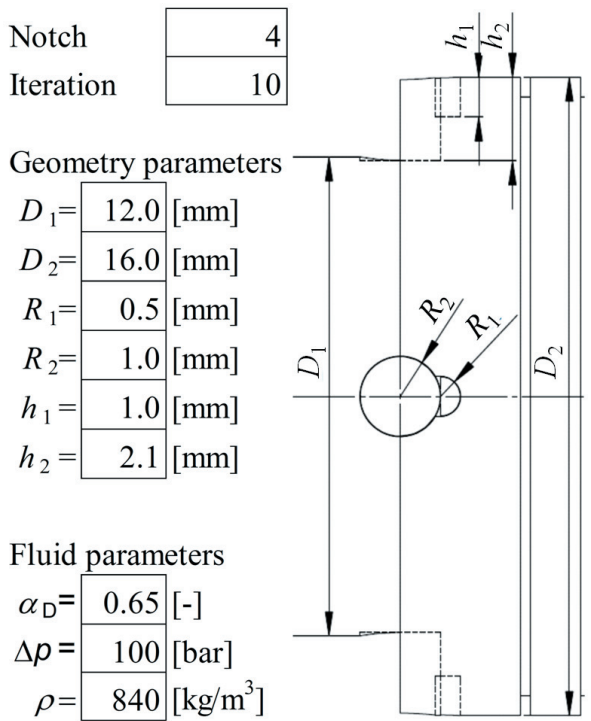

Fig. 13. Parameters for volume flow rate calculation and its corresponding geometry of the notch 
From the results of the simulation, it is obvious (Fig. 14) that there is a great difference between the values of the volume flow rates $Q\left(A_{r}\right)$ and $Q\left(A_{a}\right)$, calculated with $A_{r}$ and $A_{a}$ respectively. Minimal volume flow rate is represented by the curve $Q\left(A_{r}\right)$ which takes into account the cross-sectional area $A_{r}$ which is smaller than $A_{a}$ in each calculated point of the spool displacement.

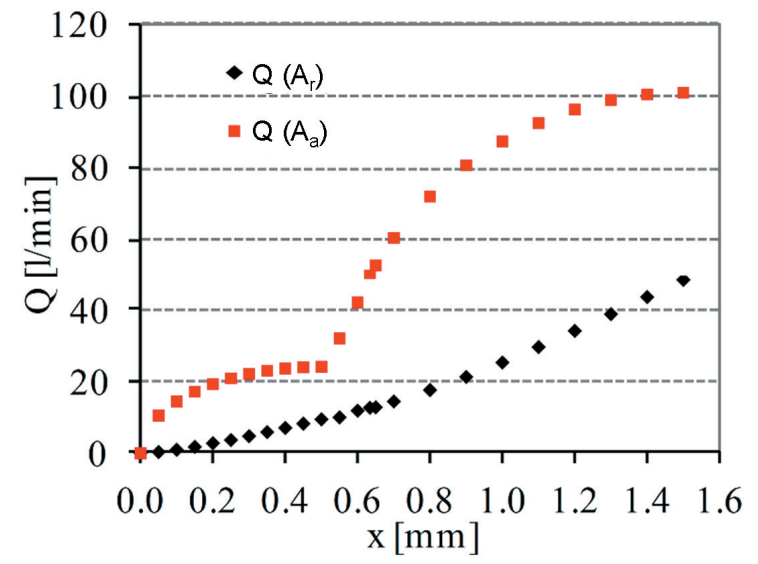

Fig. 14. Volume flow rate curves as a result of simulation models

Table 1. Simulated volume flow rates at discrete spool displacements

\begin{tabular}{ccccc}
\hline$N$ & $x[\mathrm{~mm}]$ & $Q\left(A_{r}\right)[\mathrm{l} / \mathrm{min}]$ & $Q\left(A_{a}\right)[\mathrm{l} / \mathrm{min}]$ & $Q \min [\mathrm{l} / \mathrm{min}]$ \\
\hline 1 & 0.00 & 0.000 & 0.000 & 0.000 \\
\hline 2 & 0.05 & 0.353 & 10.492 & 0.353 \\
\hline 3 & 0.10 & 0.984 & 14.443 & 0.984 \\
\hline 4 & 0.15 & 1.778 & 17.190 & 1.778 \\
\hline 5 & 0.20 & 2.800 & 19.257 & 2.800 \\
\hline 6 & 0.25 & 3.696 & 20.846 & 3.696 \\
\hline 7 & 0.30 & 4.770 & 22.062 & 4.770 \\
\hline 8 & 0.35 & 5.897 & 22.963 & 5.897 \\
\hline 9 & 0.40 & 7.062 & 23.585 & 7.062 \\
\hline 10 & 0.45 & 8.251 & 23.951 & 8.251 \\
\hline 11 & 0.50 & 9.453 & 24.071 & 9.453 \\
\hline 12 & 0.55 & 10.000 & 32.000 & 10.000 \\
\hline 13 & 0.60 & 11.860 & 42.000 & 11.860 \\
\hline 14 & 0.63 & 12.678 & 50.182 & 12.678 \\
\hline 15 & 0.65 & 12.800 & 53.000 & 12.800 \\
\hline 16 & 0.70 & 14.433 & 60.660 & 14.433 \\
\hline 17 & 0.80 & 17.610 & 72.200 & 17.610 \\
\hline 18 & 0.90 & 21.264 & 80.880 & 21.264 \\
\hline 19 & 1.00 & 25.281 & 87.555 & 25.281 \\
\hline 20 & 1.10 & 29.578 & 92.659 & 29.578 \\
\hline 21 & 1.20 & 34.085 & 96.443 & 34.085 \\
\hline 22 & 1.30 & 38.744 & 99.057 & 38.744 \\
\hline 23 & 1.40 & 43.502 & 100.593 & 43.502 \\
\hline 24 & 1.50 & 48.308 & 101.100 & 48.308 \\
\hline & & & &
\end{tabular}

At the maximal spool displacement $x=1.5 \mathrm{~mm}$, the value of the volume flow rate $Q\left(A_{r}\right)$ is $48.3 \mathrm{l} / \mathrm{min}$. The exact value of the volume flow rate at a discrete spool displacement can be seen from Table 1.

\section{EXPERIMENTAL VERIFICATION OF THE ANALYTICAL MODEL}

An experimental analysis of the valve has been performed with a real hydraulic spool valve of the KV4/3-10 type with the modified sliding spool geometry as shown in Figure 13. The HLP 46 hydraulic oil with the density of $840 \mathrm{~kg} / \mathrm{m}^{3}$ was used during the experiment. The volume flow across the metering edge was measured at the same 24 discrete spool displacement points from $x=0$ to $x=1.5 \mathrm{~mm}$ as in the simulation (Table 2). The pressure difference was set to 100 bar for every discrete spool position where the volume flow was measured.

The results of the simulation and the experiment are given in Table 2 and shown in Fig. 15.

Table 2. Simulated volume flow rates Qsim and experimentally determined volume flow rates Qexp

\begin{tabular}{ccccc}
\hline $\mathrm{N}$ & $x[\mathrm{~mm}]$ & $Q \operatorname{sim}[\mathrm{l} / \mathrm{min}]$ & Qexp $[\mathrm{l} / \mathrm{min}]$ & $\Delta Q[\%]$ \\
\hline 1 & 0.00 & 0.000 & 0.000 & 0.00 \\
\hline 2 & 0.05 & 0.353 & 0.357 & 1.01 \\
\hline 3 & 0.10 & 0.984 & 0.995 & 1.11 \\
\hline 4 & 0.15 & 1.778 & 1.800 & 1.21 \\
\hline 5 & 0.20 & 2.800 & 2.830 & 1.06 \\
\hline 6 & 0.25 & 3.696 & 3.740 & 1.17 \\
\hline 7 & 0.30 & 4.770 & 4.820 & 1.03 \\
\hline 8 & 0.35 & 5.897 & 5.960 & 1.06 \\
\hline 9 & 0.40 & 7.062 & 7.130 & 0.96 \\
\hline 10 & 0.45 & 8.251 & 8.330 & 0.95 \\
\hline 11 & 0.50 & 9.453 & 9.600 & 1.53 \\
\hline 12 & 0.55 & 10.000 & 10.160 & 1.57 \\
\hline 13 & 0.60 & 11.860 & 11.940 & 0.67 \\
\hline 14 & 0.63 & 12.678 & 12.730 & 0.41 \\
\hline 15 & 0.65 & 12.800 & 12.920 & 0.93 \\
\hline 16 & 0.70 & 14.433 & 14.550 & 0.80 \\
\hline 17 & 0.80 & 17.610 & 17.750 & 0.79 \\
\hline 18 & 0.90 & 21.264 & 21.400 & 0.63 \\
\hline 19 & 1.00 & 25.281 & 25.450 & 0.66 \\
\hline 20 & 1.10 & 29.578 & 29.780 & 0.68 \\
\hline 21 & 1.20 & 34.085 & 34.400 & 0.92 \\
\hline 22 & 1.30 & 38.744 & 39.120 & 0.96 \\
\hline 23 & 1.40 & 43.502 & 43.950 & 1.02 \\
\hline 24 & 1.50 & 48.308 & 48.800 & 1.01 \\
\hline & & & &
\end{tabular}

Experimental (Qexp) and simulated (Qsim) results presented in Fig. 15 fit very well together and therefore confirm the hypothesis of the minimal 
cross-sectional area. The measurement uncertainty of the experimental points is calculated as a standard deviation $\sigma=0.094 \mathrm{l} / \mathrm{min}$. The maximal difference between simulated and experimental values $(1.57 \%)$ appears at the spool displacement $x=0.55 \mathrm{~mm}$ which can be considered as a transition area where the large circular pocket begins. In general, the deviation between the simulated and the experimental results of the volume flow is no greater than $1.2 \%$.

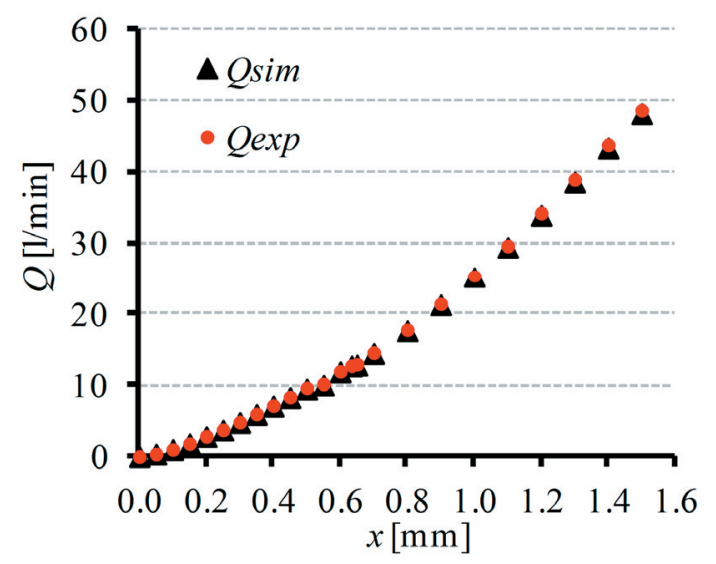

Fig. 15. Simulated and experimentally defined characteristic points of volume flow rate

\section{CONCLUSION}

This research presents the new approach to modelling and simulation of hydraulic spool valves by using simple mathematical expressions for describing the sliding spool metering edge geometry. Developed models can be implemented into any hydraulic simulation tool's library, such as MCL library of DSHplus.

The paper focuses on only one of the several different mathematical models of the specially designed metering edge volume flow characteristics that we have developed. The cross-sectional area of the metering edge has been simplified to a $2 \mathrm{D}$ geometrical area instead of using a 3D shape because the cross-sectional difference is less than $0.5 \%$.

The results of the volume flow rate shown in Table 2 are calculated by using the simulation model which took into account the minimal cross-sectional area. The data sheet table is prepared as the input parameters for the valve simulation model. The simulation results of the volume flow rate model are verified and confirmed with experimental tests.
With the use of our approach, hydraulic valves can be designed in advance, very simply and flexibly, with different shapes of spool metering edges in combination with other functional elements. Such an approach enables the user to quickly find the most appropriate spool construction for the desired hydraulic system performance during the development phase.

\section{REFERENCES}

[1] Lazić, D.V. (2010). Practical tracking control of the electropneumatic piston drive. Strojniški vestnik Journal of Mechanical Engineering, vol. 56, no. 3, p. 1-6.

[2] Detiček, E. (2011). An intelligent electro-hydraulic servo drive positioning. Strojniški vestnik - Journal of Mechanical Engineering, vol. 57, no. 5, p. 394-404, DOI:10.5545/sv-jme.2010.081.

[3] Posa, A., Oresta, P., Lippolis, A. (2013). Analysis of a directional hydraulic valve by a direct numerical simulation using an immersed-boundary method. Energy conversion and Management, vol. 65, p. 497506, DOI:10.1016/j.enconman.2012.07.012.

[4] Lisowski, E., Czyzycki, W., Rajda, J. (2013). Three dimensional CFD analysis and experimental test of flow force acting on the spool of solenoid operated directional control valve. Energy Conversion and Management, vol. 70, p. 220-229, DOI:10.1016/j. enconman.2013.02.016.

[5] Tic, V., Lovrec, D. (2012). Design of modern hydraulic tank using fluid flow simulation. International Journal of Simulation Modelling, vol. 11, no. 2, p. 77-88, DOI:10.2507/IJSIMM11(2)2.202.

[6] Herakovič, N. (2009). Flow-force analysis in a hydraulic sliding-spool valve. Strojarstvo, vol. 51, no. 6, p. 555-564.

[7] US-Patent 6.450.194 B1 (2002). Spool Notch Geometry for Hydraulic Spool Valve. Wasson, J.B., Swaim, D.W., Fiala, G.T. The United States Patent and Trademark Office, Alexandria.

[8] Herakovič, N., Noe, D. (2006). Analysis of the operation of pilot-stage piezo-actuator valves. Strojniški vestnik - Journal of Mechanical Engineering, vol. 52, no. 12 , p. $835-851$.

[9] FUIDON GmbH (2010). DSHplus. Micro Component Library, Aachen.

[10] Murrenhoff, H. (2001). Grundlagen der Fluidtechnik. Teil 1: Hydraulik. Shaker Verlag. Aachen.

[11] Mathworld, Circular segment area (2012). from http:// mathworld.wolfram.com, accessed on [2012-03-08]. 